\title{
LIBROS
}

\section{Indians, Missionaries, and Merchants. The Legacy of Colonial Encounters on the California Frontiers}

\author{
Kent G. Lighfoot \\ University of California Press, Berkeley, 2005
}

Mario Alberto Magaña Mancillas

Es fundamental en la tarea continua de la investigación histórica, entendida como el estudio científico de las sociedades humanas en el tiempo, estar revisando las nuevas aportaciones que diferentes académicos realizan a la comprensión de un tema como el proceso de los intercambios culturales en una disimetría de poder entre los agentes socioculturales de las tradiciones indígenas y de las tradiciones occidentales en el antiguo noroeste novohispano, que es un tema de especial significación para algunos investigadores, como el que reseña.

La nueva obra de Kent G. Lightfoot, profesor de antropología en la Universidad de California en Berkeley, es un suge- rente texto sobre el estudio de las transformaciones culturales de los indios de California en sus dos fronteras principales con occidente, tanto la denominada frontera misional franciscana como la frontera comercial rusa, ambas coincidentes en el norte de la bahía de San Francisco a principios del siglo diecinueve. El texto constituye una búsqueda por comprender estos procesos y su impacto en el devenir histórico de las identidades indígenas. Para ello se divide en nueve partes (ocho capítulos y unas conclusiones), de las que destacan los capítulos primero: "Dimensions and Consequences of Colonial Encounters"; segundo y tercero: "Franciscan Missions in Alta California" y 


\section{Culturales}

"Native Agency in the Franciscan Missions", y el séptimo: "Missionary and Mercantile Colonies in California: The Implications".

Indians, Missionaries, and Merchants también se distingue por hacer una aportación importante a la discusión académica sobre los intercambios culturales entre indios y occidentales en el noroeste novohispano entre mediados del siglo dieciocho y el diecinueve: la propuesta de una metodología de investigación basada en el análisis comparativo, con una perspectiva holística, multidimensional y diacrónica, basado en la antropología histórica y con un amplio manejo documental de diversos orígenes disciplinarios, principalmente la antropología, la arqueología, la historia y la etnografía:

Archaeology, archival documents, ethnographic observations, and native narratives together comprise the holistic study of historical anthropology, the most powerful approach for investigating the past, outside of a time machine. The integration of multiple lines of evidence from documentary, oral, and archaeological sources produces a broader and more inclusive view of history. [...] They allow us to hear the muted voices of the colonial past (p. I5).
Para un control de esta propuesta metodológica, Lightfoot propone que se deben estudiar las dos fronteras culturales con base en siete indicadores generales, a los que denomina "Dimensions of Colonial Encounters": I) "Enculturation Programs", 2) "Native Relocation Programs", 3) "Social Mobility", 4) "Labor Practices", 5) "Interethnic Unions", 6) "Demographic Parameters of Colonial and Native Populations" y 7) "Chronology of Colonial Encounters". Es indudable la importancia de los estudios comparativos en parámetros mucho más cercanos, como serían las dos formas de colonización emprendidas al norte de la bahía de San Francisco, tanto por empresarios rusos como por misioneros franciscanos, preferible a los estudios comparativos de regiones físicamente lejanas, como California y Bolivia.

La propuesta es muy interesante, pero en el momento de querer aplicarla con los elementos documentales sobrevivientes de ambas fronteras culturales surgen más dudas que respuestas concretas, sobre todo cuando se establece que existe una diferencia sustancial entre la forma de colonización de los mercaderes rusos y la de los misioneros franciscanos, principalmente en dos aspectos distinguibles: a) los programas o 


\section{Culturales}

proyectos de cambio cultural (para los primeros inexistentes y para los segundos parte de su visión y misión) y b) que esto implicó un control mayor por los segundos que por los primeros; es decir, los mercaderes rusos prefirieron utilizar las estructuras de poder indígenas existentes antes que imponer las estrategias de su tradición cultural occidental, como hicieron los misioneros.

Hasta aquí podríamos concordar con el desarrollo argumentativo de Lightfoot. Las dudas empiezan ante la total ausencia de otro de los elementos importantes en la frontera misional franciscana: los colonos hispanos y novohispanos que los acompañaron y condicionaron en el trabajo misional. Parecería que los franciscanos fueron los únicos hispanos en toda esa región al este y sur de la bahía de San Francisco, y no hay referencias a los proyectos de colonización con "civiles" ni a los pueblos de Branciforte y San José, por nombrar a los más cercanos y que aparecen en el mapa 9 (p. I20). Sin adentrarnos en la presencia militar, simbolizada por los presidios, ni en la actividad político-administrativa colonial, que representaba los intereses de la monarquía y del imperio, y que tantos conflictos generó entre los representantes de la corona española y los franciscanos, y no sólo en la Alta California, sino también en otras regiones novohispanas, a raíz de la implementación de las llamadas reformas borbónicas.

Pero también resalta que, a pesar de llegar a la conclusión de que esos dos aspectos señalados son la diferencia sustancial entre la frontera mercantil rusa y la frontera misional franciscana, el autor debe reconocer que las dos misiones sureñas de la Alta California, San Luis Rey y San Diego de Alcalá, en realidad tendrían un comportamiento propio de la frontera mercantil rusa y no de la franciscana, y hace una serie de aportes de investigación académica anterior que refuerza esta propuesta, llegando en las conclusiones a establecer que existen tres procesos de cambios culturales: uno referida a la frontera misional franciscana y los indígenas de las zonas centrales de California; otro con relación a las dos misiones sureñas y los indios de la zona, principalmente los diegueños, y el tercero referido a la frontera mercantil rusa y a los indios, principalmente los kashaya pomo.

Lo que no se especifica es cómo una sección de la frontera misional franciscana, en un proyecto de colonización novohispano para la Alta California, y en el marco de 


\section{Culturales}

una estrategia geopolítica de defensa de las fronteras imperiales, pudiera haber tomado medidas diferenciadas respecto a las instrucciones generales tanto para misioneros, soldados y comandantes de presidio como para colonos “civiles". Aunque no podemos negar lo provocador de la idea, ya que existen evidencias en el norte de la Baja California, en la frontera misional dominica, de que las condiciones eran muy similares a lo que Lightfoot establece para estas dos misiones franciscanas de San Luis Rey y San Diego de Alcalá respecto a este segundo proceso de cambios culturales desarrollados en las fronteras de California. Indudablemente, existen muchas aportaciones en la nueva obra de Lightfoot, pero lo más enriquecedor son las provocaciones metodológicas y académicas. Entre las primeras, la propuesta de un análisis holístico con un manejo multidimensional de diferentes fuentes de información, complementadas con los testimonios de tradición oral y los hallazgos de las investigaciones arqueológicas, que sólo tienen el inconveniente del desarrollo disciplinario respectivo, que de cierta manera el autor pudo solucionar con una formación e investigación transdisciplinaria, pero en ciertos momentos de la obra se denota que no pudo conseguir las fuentes equiparables para llevar un nivel homogéneo en los tres procesos de cambio cultural de las fronteras de California. Sin olvidar un aspecto que es importante destacar: la nula utilización de documentos en su idioma original para la frontera misional franciscana, que siempre tendrá el problema del manejo del lenguaje y la idiosincrasia, sobre todo para la reconstrucción de aspectos identitarios.

Por último, existe un punto muy interesante en el capítulo octavo ("The Aftermath") de la obra de Kent G. Lightfoot, y que tiene que ver con el impacto de los académicos en la construcción del conocimiento sobre los grupos indígenas de California. Nos referimos, sobre todo, a los trabajos pioneros de los antropólogos encabezados por Alfred Kroeber ("Anthropology and Tribal Recognition”, pp. 222232). Esto lleva a Lightfoot a plantear que en la búsqueda del indio "verdadero" los antropólogos privilegiaron a ciertos grupos e individuos que ellos consideraron como menos compenetrados en la tradición cultural de Occidente, y que de cierta manera fueron muy estudiados, en prejuicio de otros grupos e individuos que, por tanto, dejaron de ser "indios", ya que los oficiales del gobierno estadunidense 


\section{Culturales}

se basaron en los estudios de los antropólogos para las identificaciones y reconocimientos, vía las reservaciones, de los grupos debidamente acreditados para poder reclamar derechos sobre terrenos tradicionales.

El tema resulta muy provocador, y lo que llega a demostrar Lightfoot es que debemos comprender en su momento histórico toda esa nomenclatura sobre los grupos indígenas de California, y en general del noroeste novohispano, que aceptamos como verdad inamovible:
Although recognizing the important and pioneering contributions that Kroeber and other early ethnographers made to our understanding of Native Californians, we must rethink the legacy of viewing Indians as a static, traditional people. Native societies, both today and in the past, are dynamic and continually in transformation in relation to everchanging social conditions. Constructing a more encompassing and inclusive historical perspective on California Indians means appreciating the many roads these people have traveled in getting to today (p. 239).

Indians, Missionaries, and Merchants. The Legacy of Colonial Encounters on the California Frontiers

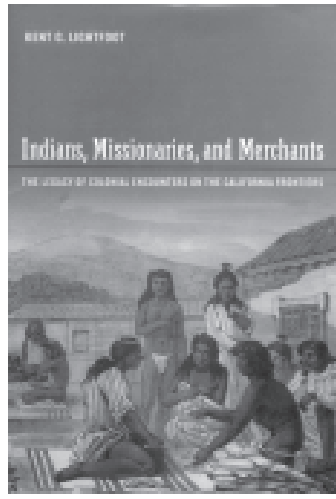

Kent G. Lighfoot

University of California Press, Berkeley, 2005, 338 pp. 